\title{
Design And Simulation Of A Deep -Water Bucket Foundation
}

\author{
Dewei Li,Xiaofeng Su,Lei Yang,Baogang Li, Lei Yang,Yugang Ren
}

China Nation Deep Sea Center, Weiyang Road Aoshanwei Street Jimo Qingdao China

Keywords:Deep - sea oil and gas fields; Bucket foundation; design;Simulation

\begin{abstract}
In this paper, combined with the demand of deep-sea oil and gas exploration and development in China, the deep-sea bucket foundation for the specific research object, to carry out the barrel-shaped foundation cylinder structure, deep sea motor and pump structure under pressure environment design and tube structure stress, safety factor, Simulation Analysis of Deformation.
\end{abstract}

\section{Introduction}

With the depletion of land resources, human survival and development will be increasingly dependent on the ocean. Large-scale and comprehensive development and utilization of marine resources and space, the development of marine economy has been included in the coastal countries of the development strategy ${ }^{[1]}$. The oceans occupy more than $70 \%$ of the earth's surface and contain abundant resources. $70 \%$ of the total reserves of oil and gas resources on the planet are found in the oceans ${ }^{[2]}$. China has a vast continental shelf, rich in oil and gas resources, has proven industrial value of offshore oil and gas fields, including the Bohai Sea, the Yellow Sea, the East China Sea and the South China Sea all Chinese waters, forming an annual output of 10 million tons of the original production capacity. In the modern ocean development, the development of marine oil and gas is the most noticeable ${ }^{[3]}$.

\section{Working principle}

The suction bucket foundation is an open-bottomed cylinder with a valve mounted at the top to create a pressure drop across the top of the suction bowl to achieve barrel installation. In the first stage of the installation, the suction foundation is inserted into the soil by its own weight, and the second stage pumps the seawater between the top of the cylinder and the soil layer by a pump. After reaching a predetermined depth, the valve at the top of the installation bucket closes to increase the cylinder's natural The efficiency of this method is generally low in clay, and is better in deep, evenly soft soils or clean sandy environments.

\section{Design of deep sea electric motor}

In general, the structure of deep-sea submersible motors in three ways: closed pressure, the AC or DC motor mounted in a closed enclosure, the motor output shaft at the sealing device. This structure can directly use the standard specifications of the motor, but the motor output shaft at the dynamic seal is outside the high-pressure rotary seal, a slight leakage will cause fatal damage to the motor. In addition, the closed housing to withstand high ambient pressure, resulting in a significant increase in the size and weight of the motor; liquid filled, the motor stator or the entire motor in a sealed body, the motor seal in vitro connection compensator, through the compensator to external The pressure is transmitted to the motor housing liquid; direct immersion, such motor has two kinds of structure, one is completely enclosed, water filled them; the other is open, the two motor requirements and good in the water Insulation materials and protective equipment, its life depends on the protection of equipment ${ }^{[5]}$.

The first of the three schemes above is due to the volume of the motor, the weight is large and because of the seal of the motor rotating shaft, the structure is complex and the reliability is not high. The third scheme is equivalent to using the stator and rotor of the motor, Of the shell, to a certain 
extent, reduce the weight of the deep-sea motor, but the cost is slightly higher; The second program can be used as the existing motor packaging, the use of external pressure compensator for transmission, only the appropriate design transformation To meet the deep sea $1500 \mathrm{~m}$ working environment requirements, so the best solution.

\subsection{Design of Motor Installation}

As a result of the general brush motor commutation generated when the spark will be carbonated compensation oil, resulting in short-circuit the motor rotor, damage to the motor, difficult to use in the deep-sea motor. The simulation of the use of brushless DC motor to transform, taking full account of the corrosion resistance of motor materials and shrinkage conditions, the use of good insulation properties of the capacitor oil as compensation oil.

To be used to brushless DC motor for the two:

1) $733 \mathrm{~W}, 48 \mathrm{VDC}$, rated torque $1.4 \mathrm{~N} * \mathrm{~m}$, rated current $20 \mathrm{~A}$, rated speed 5000rpm, Inorganic adjustable speed, the output increased speed reducer, the output torque $20 \mathrm{~N} * \mathrm{~m}$, output speed 200rpm;

2) $366 \mathrm{~W}, 48 \mathrm{VDC}$, rated torque $1.4 \mathrm{~N} * \mathrm{~m}$, rated current $10 \mathrm{~A}$, rated speed $2500 \mathrm{rpm}$.

According to the size of the motor, taking into account the installation, fixing, cylinder seal and shaft extension and bearing installation of the motor in the sealed cylinder, the design of motor cylinder diameter $126 \mathrm{~mm}$, outside diameter $173 \mathrm{~mm}$, length $390 \mathrm{~mm}, 145 \mathrm{~mm}$ at one end of the cylinder An additional convex circular platform, along the platform diameter of $136 \mathrm{~mm}$ circle evenly drill eight M5 holes to install the motor.

\subsection{End cover design}

The motor installed in the form of external compensator tube, the cylinder without the need for pressure, but still need to solve the motor in the water under the work of the sealing problem, there are static seal and the motor output shaft rotation seal two.

\section{1) Static seal}

O-type sealing ring is the most commonly used method in static sealing. O-type sealing ring is used between the groove and the sealing surface. The rebound force caused by rubber pressure gives a certain initial sealing pressure to the contact surface to form pre-sealed. The $\mathrm{O}$ type sealing ring in the pre-tightly sealed state is pressed by the fluid pressure to the groove side and the pressure is transmitted to the contact surface through the rubber material so that the pressure at the contact surface is greater than the internal pressure to form a self-sealing ${ }^{[6]}$. The microscopic mechanism of self-tightening: The rubber material is pressed into the microscopic depression of the metal surface at the contact surface, forming a closed block of sealing tape. The amount of compression deformation is expressed by the compression ratio:

$$
\varepsilon=\frac{d_{2}-H_{0}}{d_{2}} \times 100 \%
$$

Where: d2-sealing ring cross-section diameter (mm);H0-Sealing groove bottom distance Seal height ( $\mathrm{mm})$.

\section{2) Rotating seal}

Motor driven in the deep water pump work, the motor output shaft rotation seal more difficult. For low-speed rotary shaft, the main use of O-type sealing ring, high-speed rotating motor, the use of O-type sealing ring will lead to wear ring, fever, leakage. After consulting with a specialist, choose a W-Shaped Combination Seal for the shaft. The type of seal by a W-type seal ring and an O-type sealing ring combination, suitable for internal and external sealing, with good sealing performance, low friction, no crawling phenomenon, simple structure and easy installation. W-type seal ring using PTFE and carbon fiber materials, with good toughness, high and low temperature resistance, acid and alkali wear, good thermal conductivity characteristics. O-type sealing ring oil-resistant seawater using fluorine rubber, motor output shaft diameter $14 \mathrm{~mm}$, select W-type rotary combination of the size of the seal $15 \mathrm{~mm} * 19.9 \mathrm{~mm} * 2.2 \mathrm{~mm}$.

The output shaft diameter of $15 \mathrm{~mm}$, in order to ensure a good sealing effect, the use of split-end groove on the cover, according to Table 1 slotted hole design, and seal the end cap to set the radial O-type sealing ring static seal. 
TABLE I. COMBINED RotARy SEAL GROOVE SizE

\begin{tabular}{|c|c|c|c|c|c|c|}
\hline $\begin{array}{c}\text { Shaft } \\
\text { diameter } \\
d f 8\end{array}$ & $\begin{array}{c}\text { Groove } \\
\text { bottom } \\
\text { diameter } \\
\text { D H9 } \\
\end{array}$ & $\begin{array}{c}\text { Groove } \\
\text { width } \\
L_{0}^{+0.2}\end{array}$ & $\begin{array}{c}\text { O-type } \\
\text { Sealing } \\
\text { ring cross } \\
\text { - section } \\
\text { diameter } \\
d 2 \\
\end{array}$ & $\begin{array}{c}\text { Fillet } \\
\boldsymbol{R} \leq\end{array}$ & $\begin{array}{c}\text { Radial } \\
\text { clearan } \\
\text { ce } \\
S \leq\end{array}$ & $\begin{array}{c}\text { Chamfe } \\
\text { ring } \\
Z \geq\end{array}$ \\
\hline $6 \sim 18.9$ & $\mathrm{~d}+0.49$ & 2.2 & 1.8 & 0.5 & 0.15 & 1.5 \\
\hline
\end{tabular}

\section{3) End cover opening}

DC brushless motor work to be connected to a 3-core phase line, a 5-core Hall signal detection line, the motor driver by detecting the Hall signal to determine U, V, W phase, adjust the PWM output signal, To achieve the motor drive, signal acquisition and control purposes.

Therefore, the motor installation cylinder two cylinder lid need four different aperture, respectively, the installation of the motor phase socket, Hall signal socket, oil compensation and motor output shaft. The diameter of the output shaft of the motor is set to $15.3 \mathrm{~mm}$ according to Table 1 , and the required diameter of oil compensator is set to G1 / 4 according to the compensator design. According to Subconn samples select 3-pin high current socket BHB3M, each core current 25A, voltage $600 \mathrm{~V}$; 5-pin standard circular male socket BH5M, 6A per core, voltage $600 \mathrm{~V}$, with nut gasket, install two watertight socket The required pore size is 5 / 8-18-2B, 7 / 16-20-2B.

\subsection{External Compensator Design}

In order to achieve the normal work of the brushless DC motor, in addition to solve the motor seal, the need to address the sealed motor cylinder oil compensation:

$$
\begin{aligned}
& V_{B} \geq \Delta V_{Y(Y)}+\Delta V_{Y(W)}+\Delta V_{Q(Y)}+ \\
& \Delta V_{Q(W)}+\Delta V_{L}+\Delta V_{G}+\Delta V_{B G}
\end{aligned}
$$

Where: $V_{B}$-Compensator working volume, m3; $\Delta V_{Y(Y)}$ -Volume change in pure working fluid with pressure change, m3.

$$
\Delta V_{Y(Y)}=\beta \cdot V_{Y} \cdot P_{J}
$$

Where: $\beta$-the relative volume of the compression factor;

$V_{Y}$-the liquid system volume, m3; ${ }^{P_{J}}$-hydrostatic pressure, Mpa.

$$
\beta=\frac{a+2 b P_{J}}{1+a P_{J}+b P_{J}^{2}}
$$

Where: $\mathrm{a}, \mathrm{b}$ is the empirical constant, for mineral oil:a $=6.13 \times 10-4, \mathrm{~b}=1115 \times 10-9 ; \quad \Delta V_{Y(W)}$-volume change of pure working fluid with temperature change, $\mathrm{m} 3$.

$$
\Delta V_{Y(W)}=\alpha \cdot \Delta t \cdot V_{y}
$$

Where: ${ }^{\alpha}$-the volume expansion temperature coefficient, to the general oil, $\alpha=5.8 \times 10-4 \sim 9.5 \times 10-4 ; \Delta t$-temperature changes ${ }^{\circ} \mathrm{C} ; \Delta V_{Q(Y)}$-gas volume change with pressure change, $\mathrm{m} 3$, when the depth of the dive is large, the gas volume can be small to negligible extent, $\Delta V_{Q(Y)}=0 ; \Delta V_{Q(W)}$-gas volume change with temperature change, $\mathrm{m} 3$.

$$
\Delta V_{Y(Q)}=V_{Y} \cdot K_{X}
$$

Where: KX-the gas-liquid coefficient, generally take $3 \%$ to $6 \% ; \Delta V_{L-48}$ hours of liquid system leakage, m3; $\Delta V_{G}$-the volume of compensation required for the operation of the system, m3; $\Delta V_{B G}$-the change in the working volume of the compensator as a function of pressure and temperature, $\mathrm{m} 3$. Compensator and liquid system for the uniform liquid conditions, the change value is:

$$
\Delta V_{B G}=V_{B} \cdot C
$$

Where: C-compensate volume change system.

$$
C=\Sigma \Delta V / V_{Y}
$$

$\Sigma \Delta V$-the volume of the working fluid that is compensated in the system.

$$
\begin{aligned}
& \Sigma \Delta V=V_{Y}\left(\beta P_{J}+\alpha \Delta t+K_{X}\right) \\
& +\Delta V_{L}+\Delta V_{C}
\end{aligned}
$$

Therefore, the working volume of the compensator to do a kind of expression: 


$$
\begin{aligned}
& V_{B}=\frac{V_{Y}\left(\beta P_{J}+\alpha \Delta t+K_{X}\right)}{1-C} \\
& +\frac{\Delta V_{L}+\Delta V_{G}}{1-C}
\end{aligned}
$$

In this design, the inner diameter of the motor cylinder is $\mathrm{R}=126 \mathrm{~mm}$, length is $\mathrm{L}=390 \mathrm{~mm}$, volume is $\mathrm{V}=0.00486 \mathrm{~m} 3$.

Assuming that the temperature of the motor cylinder at the deck is $22^{\circ} \mathrm{C}$ and the temperature of the submerged water is $2{ }^{\circ} \mathrm{C}$, the temperature difference $\Delta t$ is 20 . According to (6), the compensator's temperature changes arising $\Delta V_{Y(W)}$ $=0.00008748$. According to (7), can be obtained with the compensator temperature changes in the gas volume change value $^{\Delta V_{Y(Q)}}=0.000243$.

Assuming that the motor barrel design is good, no leakage in the water $\Delta V_{L}=0$, the system does not need to compensate for the volume $\Delta V_{G}=0$.The working fluid volume compensated by the motor barrel at a depth of $1500 \mathrm{~m}$ underwater is obtained $\Sigma \Delta V=0.00054048 \mathrm{~m} 3$.

Finally,according to (10), the work volume of the compensator is $6.08 \times 10-4 \mathrm{~m} 3$ when the motor cylinder is working under $1500 \mathrm{~m}$. This can determine the motor cylinder volume is $4.86 \mathrm{~L}$,compensator volume is $0.7 \mathrm{~L}$, the amount of compensation accounted for about $15 \%$ of the original volume, in line with design experience.

According to the above calculation results, select 1.6Lx144-A type rubber bladder, fully consider the oiling,connection, exhaust designed to protect the shell of the bladder. There are three G1 / 4 fast jacks on the bottom of the compensator. The left and right are used to connect the manual hydraulic pressure source, the motor mounting cylinder, and the top for exhausting during the filling process. Remove the quick plug from the side of the manual hydraulic pressure source after oiling, and tighten the top exhaust port.

\subsection{Electronic cabin design}

Deep-sea pressure electronic cabin, you can use titanium and aluminum alloy. Titanium alloy pitting corrosion, acid corrosion, stress corrosion resistance is strong, low temperature, can still maintain its mechanical properties. But the poor thermal conductivity, poor rigidity, easy deformation, processing difficult, comprehensive cost is high.

Aluminum alloy has excellent electrical conductivity, thermal conductivity and corrosion resistance, low temperature, the strength increases without brittleness, is a good low-temperature device materials, and because of its good plasticity and forming processing performance, the price is much lower than the titanium alloy.

Therefore, the pressure of electronic cabin material selection of cold-forged 7075-T651 aluminum alloy. Its physical properties and mechanical properties are: tensile strength $550 \mathrm{MPa}, 0.2 \%$ yield strength $524 \mathrm{MPa}$, elongation $11 \%$, elastic modulus $71 \mathrm{GPa}$, hardness $150 \mathrm{HB}$, density $2810 \mathrm{~kg} / \mathrm{m} 3$, Poisson ratio 0.3. In order to improve the corrosion resistance, after the completion of the processing of electronic cabinets and their end caps using anodized black surface treatment.

\section{1) Computational theory}

According to the instability of the situation can be divided into three types of external pressure cylinder: Long cylinder: rigid head on the middle of the cylinder can not afford effective deformation support, the most likely to collapse instability, the number of ripples $n=2$ flat round; Cylinder: the end of the head on the deformation of the cylinder has a restraint effect, destabilization failure wave number $n>2$, there are three waves, four waves and other curved waves; rigid cylinder: If the cylinder is short, Of the rigidity, and will not damage due to instability.

\section{2) Safety factor}

For the underwater pressure structure, the safety factor specified by the national norms are different, China's submersible design specifications and the United States (ABS) provides the calculation of pressure to take the work pressure of 1.5 times. British Lloyd's Code requirements, calculate the pressure with the depth of the multiples of the change, the law is as follows:

\begin{tabular}{l|lllllll} 
Depth $(m)$ & 50 & 100 & 200 & 300 & 400 & 500 & 600 \\
\hline Safety Factor & 2.5 & 2.4 & 2.2 & 2.0 & 1.9 & 1.8 & 1.7
\end{tabular}

The design of the pressure shell working depth $1500 \mathrm{~m}$, design calculation depth of $6000 \mathrm{~m}$, safety factor of 4 , to meet the requirements.

\section{3) Initial thickness estimation}


Cylindrical shell from the simple theory of thin film geometry and shell thickness, thickness by the following formula:

$$
S \approx \beta_{1} \frac{P_{C} \cdot R}{\sigma_{S}}
$$

Where: PC-the design failure pressure; R-average radius of the cylinder; $\sigma_{s}$ - the material yield strength, $\beta_{1}$-the reduction factor.

According to the size of the actuator placed in the cylinder, to determine the cylinder diameter of $106 \mathrm{~mm}$, length of $230 \mathrm{~mm}$, according to (11), can be estimated to the initial thickness of $12 \mathrm{~mm}$.

\section{4) Thickness verification}

According to the estimated initial thickness, the cylinder thickness is $15 \mathrm{~mm}, L_{k 1}=1.17 D \sqrt{\frac{D}{S}}=420>230 \mathrm{~mm}$.

So here according to the short cylinder formula to verify the design thickness:

$$
P_{k}=2.6 E \frac{\left(\frac{S}{D}\right)^{2.5}}{\frac{L}{D}}=525 \mathrm{MPa} \quad S=\frac{P_{k}}{P}=8.75
$$

In fact, because $\mathrm{S} / \mathrm{D}=0.12>0.4$, The pressure cylinder has been established rigid cylinder, the destruction is due to the cylindrical wall of the compressive stress exceeds the material design temperature of the yield baseline, there is no stability problem, according to the strength of the formula can be calculated safety coefficient of 1.08.To meet the design requirements.

The barrel is made of 304 stainless steel. The barrel height is $65 \mathrm{~cm}$ and the diameter is $40 \mathrm{~cm}$. The top of the closed plane leaving the outlet and inclination instrument mounting bracket, the barrel side of the displacement sensor is designed to install the slot.

It is verified by calculation that the seal performance, pressure resistance and weight of the whole structure of the deep-sea bucket foundation structure are in accordance with the operating requirements under the deep sea pressure.

\section{References}

[1] Zhiyong Zhang.Environmental Analysis of Marine Engineering Development and Market Investment Forecast.[J]. Ocean engineering.2005,(237):28-30.

[2] Huifen Cao. Development Trend of Deep - sea Oil and Gas Drilling Equipment in the World. [J].Ocean engineering.2005,(237):24-27.

[3] Weilinag Jin. Some mechanical problems in ocean engineering. $[\mathrm{J}]$. Bulletin of Science and Technology.1997(2):86-92.

[4] Liqin Wang. Suction - type foundation installation of key equipment deep water pump skid block.[J]. Chinese shipbuilding.2012(6):121-122.

[5] Bo Zou. Research on Sealing Performance of Rotating Shaft of Deep Sea Motor.[D]. Southwest Jiaotong University.2008(5).

[6] Hongying Cui. Selection of the O type Sealing ring.[J]. coal.2007(2):117-118. 